\title{
Geometric Feature Extraction of Selected Rice Grains using Image Processing Techniques
}

\author{
Sukhvir Kaur \\ School of Electrical Engg. \& IT \\ COAE\&T, PAU \\ Ludhiana, India
}

\author{
Derminder Singh \\ School of Electrical Engg. \& IT \\ COAE\&T, PAU \\ Ludhiana, India
}

\begin{abstract}
Rice grains quality estimation is important in fulfilling customer requirements. Geometric features of grains are used to check the quality of rice grains. Mechanical classification methods are being used largely by local industry to grade different size of food grains on basis of geometric parameters. Image processing techniques can be applied to extract various features of rice grains and classifies the grains based on geometric features. This study proposed a method that processes the captured still digital image of rice grains. The program has been developed using MATLAB technology. The compiler of this technology was used to convert the program into standalone application. Application was embedded with MATLAB compiler runtime that enables the execution of compiled application on computers that do not have this technology installed. In this method seven geometric features of individual rice grain were extracted from digital images and then grains of particular varieties were classified into three different classes. Calibration factor was calculated to make the method independent of camera position. The method was tested on five varieties of rice grains and compared to experimental results by measuring the geometric features of rice grains using digital vernier caliper. The error rate of measuring different geometric features between proposed method and experimental analysis was found between $-1.39 \%$ and $1.40 \%$.
\end{abstract}

\section{General Terms}

User Interface, Calibration Factor

\section{Keywords}

Rice grains, Classification, Feature Extraction, Image Processing

\section{INTRODUCTION}

Rice is produced in several areas throughout the world. Preceded by China, India is at second position in yield of rice in the whole world. Rice is main food of $80 \%$ of the people in South East Asia [6]. Good quality rice grains are demanded by the customer because every country now becomes self sustaining in rice production. Many parameters are required to be judged for finding the rice grains quality. Techniques need to be developed for processing of rice grain images and require automation of system to find the quality of rice grains.

Basically, quality of the rice grains is based on geometric features. Grains obtained after performing mechanical operations by machines varies in size approximately $37.5 \%$. These require finding geometric feature of rice grains and classification.
Computer vision basically involves image analysis and image processing which are the important aspects. To improve the quality of an image, a large number of operations are performed. Such operations involve removal of various defects as improper focus, repetitive noise, geometric distortion, camera motion and non-uniform lighting. For taking decisions in system to control application the image analysis is used to differentiate the interested area from background region [11].

Brosnan gives review of system for online automatic grain inspection using machine vision which was developed by Wan, Lin and Chiou [1]. Related to rice kernel sixteen attributes were identified which were based on defects and kernel colour for rice quality estimation in three different classes. Cracked, sound, broken, chalky, dead, immature, offtype, paddy broken and destroyed brown kernels of rice were identified and system classified these with a low error rate than by manual work. The inner blemish of rice grain can be estimated by various techniques in image processing as modified dark field illumination method. Liu proposed a method based on morphological and color in digital image processing for identification of rice seeds of the six varieties which are available in Zhejiang Province [7]. Guzman investigated the usage of a computer vision techniques and multilayer neural networks for efficiently finding the sizes, variety and shapes of 52 samples of rice grains related to five groups of varieties of rice grain in the Philippines [4].Shantaiya performed the work by using Image analysis and image warping approach [10]. To find the unknown grain varieties, a network was trained. Patil presents the study on distinct color models which involve $\mathrm{L} * \mathrm{a} * \mathrm{~b}$, HSI, HSV, and $\mathrm{YCbCr}$ were used for finding and categorizing the food grains by taking color and basic texture attributes in consideration[9]. Maheshwari presents a quality analysis of Gujarat-17 rice seeds via image analysis [8]. They identify normal seed and foreign elements present in a given sample using a proper image acquisition system. Gujjar provides a method to accomplish morphological and texture based retrieval on a rice grain images of Basmati [3]. To find the unknown grain varieties, a network was used, which was trained to analyze features. Percentage purity of rice grain sample of basmati which was hulled was determined by various images processing method. Kaur trains the SVM model by training set, where as model working was tested on independent test [6].The transformed training pattern vectors were used to train the kernel of the RBF along with support vector machine and then tested by using specific methods. Nine rice varieties were classified based on different sides of grain and other parameters [2]. 


\section{MATERIAL AND METHODOLOGY}

\subsection{Material}

For determining physical dimensions five varieties of rice grains were used -Pusa basmati 1509, Pusa basmati 1121, Pusa 44, PR121 and PR122 by using MATLAB .The images of rice grains were acquired on black background with a Sony Digital Camera. The grains were not overlapped with each other. The image of known region length was captured on white background for calculating calibration factor. A digital vernier caliper $1112-150$ of $0.01 \mathrm{~mm}$ least count was used for manual determination of length and width of rice grains.

\subsection{Methodology}

Figure (1) describe the various steps in program development and Figure (2) describe the various steps in overall application development.

\subsubsection{Image Acquisition}

The images of five rice grain varieties Pusa basmati 1509, Pusa basmati 1121, Pusa 44, PR121 and PR122 were taken for processing and stored in different formats. MATLAB technology is used for performing operations on image.

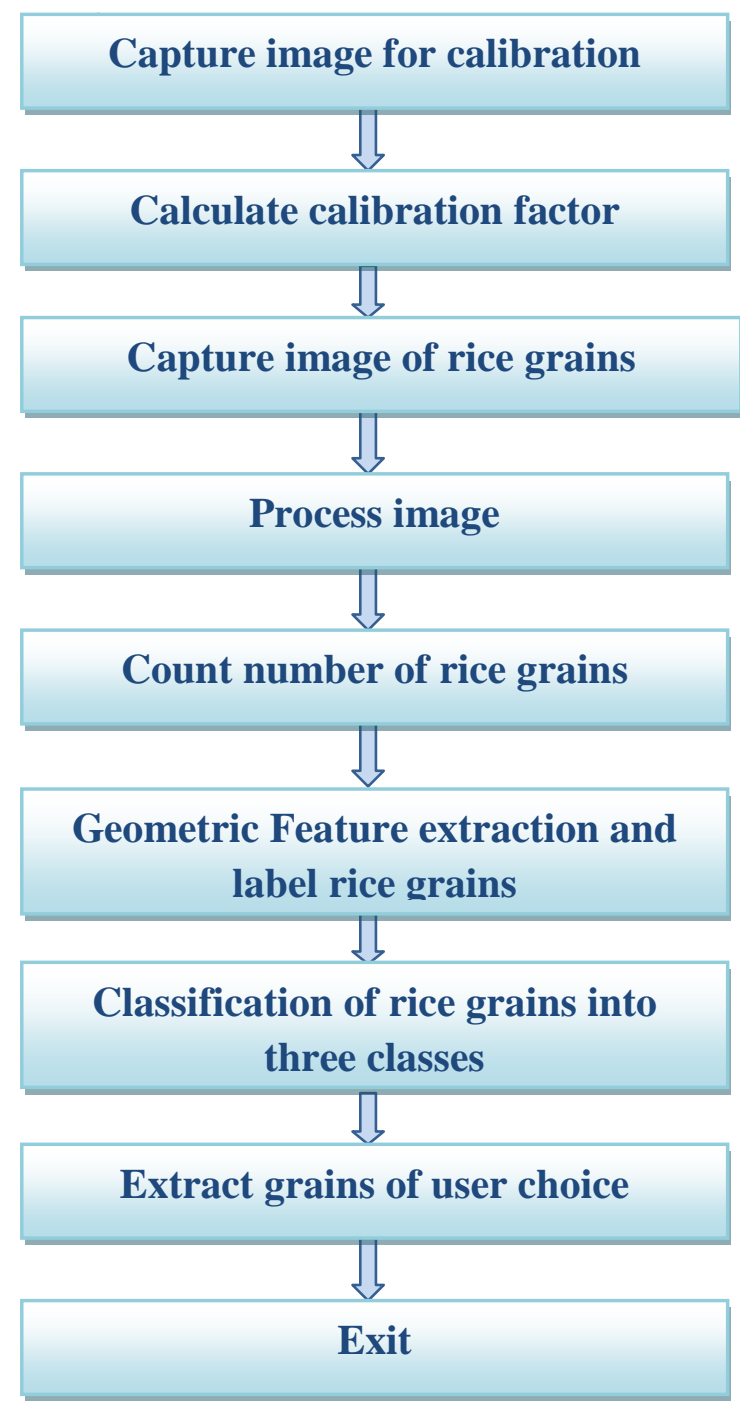

Fig.1. Steps in Program Development

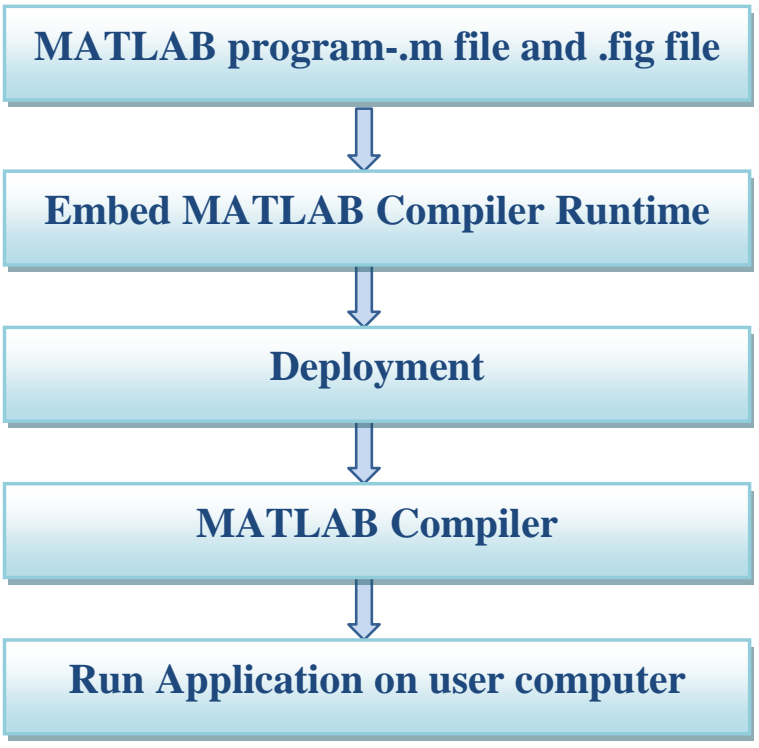

Fig.2. Steps in Application Development

\subsubsection{Image Processing}

Image processing is one of the important steps for the enhancement of quality of the captured image. To improve the performance various operations involves such as removal of various defects as improper focus, repetitive noise, geometric distortion, camera motion and non-uniform lighting. The Median filtering is applied for image smoothing. Then the grayscale image is binaries. Once the image is binaries morphological operations are performed.

2.2.2.1 RGB to Gray: Imread function provides RGB image of values of colour intensity ranging within 0 255.Colour information is not required to extract geometric features. As binary image is needed to perform operations on image .The image requires conversion into binary. RGB image is first converted into gray scale image.rgb2gray function is used to convert RGB image into gray scale image.

2.2.2.2 Binary Image: The image is converted into binary image which contains pixel intensity values 0 and 1.The image contains noise which can be removed by filtering .On binary image, filtering method is applied to get information regarding desired area of interest accurately.im 2 bw function is used to convert image into binary.

2.2.2.3 Image Filtering: Images cannot be used directly due to disruption made by the poor contrast and variation in intensity. In this, certain image characteristics are explained by transforming pixel intensity values:-

1) Enhancement: helps to improve the contrast of the image

2) Smoothing: Smoothing removes the noise from the image. Different types of filtering technique are used for smoothing purpose. This proposed work uses median filter to remove noise by function medfilt2 ( ). Pre-processing steps include filtering to improve the image for later processing. While removing noise it also preserves the edge information.

\subsubsection{Feature Extraction}

First, the number of pixels was calculated in $1 \mathrm{~cm} * 1 \mathrm{~cm}$ for calibration. Number of components was calculated from binary image. Then, the features extracted from image of rice grains are as follows:

1. Major Axis Length: Number of pixels between the extreme points of longest line along the length of the rice grain. 
2. Minor Axis Length: Number of pixels between the extreme points of longest line along the width of the rice grain.

3. Eccentricity: The eccentricity is calculated by fraction of the number of pixels between the major axis length and foci of the ellipse. The value of eccentricity is between 0 and 1 .

4. Perimeter: Total number of pixels which makes the boundary of rice grains.

5. Area: Total number of pixels in rice grain image.

6. Orientation: The angle between horizontal axis and major axis.

7. Aspect Ratio: It was the major axis length divided by minor axis length.

\subsubsection{Classification}

Based on the major axis length the grains percentage of long, medium and small was calculated. Largest value of major axis length was stored to extract the particular rice grains. The percentage of largest value above which grain was extracted taken from dialog box. The grains of greater value of major axis length than the percentage of largest grain was displayed.

\subsubsection{Application Development}

MATLAB .m and .fig file was embedded with MATLAB compiler runtime by deploytool.This application enables the execution of compiled application on computers that do not have MATLAB installed.

\subsubsection{Measure parameter value with digital vernier caliper}

Parameters of rice grains are determined experimentally by digital vernier caliper having a least count of $0.01 \mathrm{~mm}$ for validation purpose. Design of graphical user interface is shown in figure 5 .

\section{RESULTS AND DISCUSSIONS}

A) Mean geometric values of Major axis length and Minor axis length of fifteen rice grains of five varieties were calculated by proposed method and digital vernier caliper. The results of five rice grains varieties are given in the table I. The error rate of measuring different geometric features between proposed method and experimental analysis was found between $-1.39 \%$ and $1.40 \%$.

Table I. Values of five varieties measured from proposed method and digital vernier caliper

\begin{tabular}{|l|l|l|l|l|}
\hline \multicolumn{2}{|l|}{} & $\begin{array}{l}\text { Analytical } \\
\text { method }\end{array}$ & $\begin{array}{l}\text { Experimental } \\
\text { method }\end{array}$ & $\begin{array}{l}\text { Error } \\
(\%)\end{array}$ \\
\hline $\begin{array}{l}\text { Rice } \\
\text { grains } \\
\text { variety }\end{array}$ & $\begin{array}{l}\text { Geometric } \\
\text { Features }\end{array}$ & Mean(mm) & Mean(mm) & \\
\hline $\begin{array}{l}\text { Pusa } \\
\text { basmati } \\
1121\end{array}$ & $\begin{array}{l}\text { Major axis } \\
\text { length }\end{array}$ & 6.67 & 6.76 & -1.33 \\
\hline $\begin{array}{l}\text { Minor axis } \\
\text { length }\end{array}$ & 1.11 & 1.10 & 0.90 \\
\hline
\end{tabular}

\begin{tabular}{|c|c|c|c|c|}
\hline Pusa 44 & $\begin{array}{l}\text { Major axis } \\
\text { length } \\
\text { Minor axis } \\
\text { length }\end{array}$ & 0.98 & 0.97 & $\begin{array}{l}1.38 \\
1.03\end{array}$ \\
\hline PR121 & $\begin{array}{l}\text { Major axis } \\
\text { length } \\
\text { Minor axis } \\
\text { length }\end{array}$ & $\begin{array}{l}7.78 \\
1.33\end{array}$ & $\begin{array}{l}7.89 \\
1.34\end{array}$ & $\begin{array}{l}-1.39 \\
-0.74\end{array}$ \\
\hline PR122 & $\begin{array}{l}\text { Major axis } \\
\text { length } \\
\text { Minor axis } \\
\text { length }\end{array}$ & $\begin{array}{l}7.35 \\
1.47\end{array}$ & $\begin{array}{l}7.43 \\
1.49\end{array}$ & $\begin{array}{l}-1.07 \\
-1.34\end{array}$ \\
\hline $\begin{array}{l}\text { Pusa } \\
\text { Basmati } \\
1509\end{array}$ & $\begin{array}{l}\text { Major axis } \\
\text { length } \\
\text { Minor axis } \\
\text { length }\end{array}$ & 6.91 & 6.82 & 1.40 \\
\hline
\end{tabular}

B) Comparison of Major axis length of Pusa basmati 1509 rice grains calculated by proposed method and digital vernier caliper is illustrated in figure 3 .

C) Comparison of Minor axis length of Pusa basmati 1121 rice grains calculated by proposed method and digital vernier caliper is illustrated in figure 4 .

D) Extraction of grains whose length is more than $90 \%$ of largest grain is shown in figure 5 .

E) Comparison of Major axis length of Pusa basmati 1509 rice grains in different image formats is shown in figure 6. Five types of rice grains were used for the determination of physical dimension-Pusa basmati 1509, Pusa basmati 1121,

Pusa 44, PR121 and PR122. The digital images of grains were stored in different formats such as bmp, png, jpg and gif.

F)Geometric features of 18 rice grains of Pusa basmati 1509 variety by proposed method are calculated and then grain values were experimentally checked by digital vernier caliper.

The error between the value of major axis length obtained from application and digital vernier caliper for Pusa basmati 1509 is $1.40 \%$. Geometric features of 18 rice grains of Pusa basmati 1509 are shown in table II. Seven geometrical features are Major axis length, Minor axis length, eccentricity, area, orientation, perimeter and aspect ratio. 


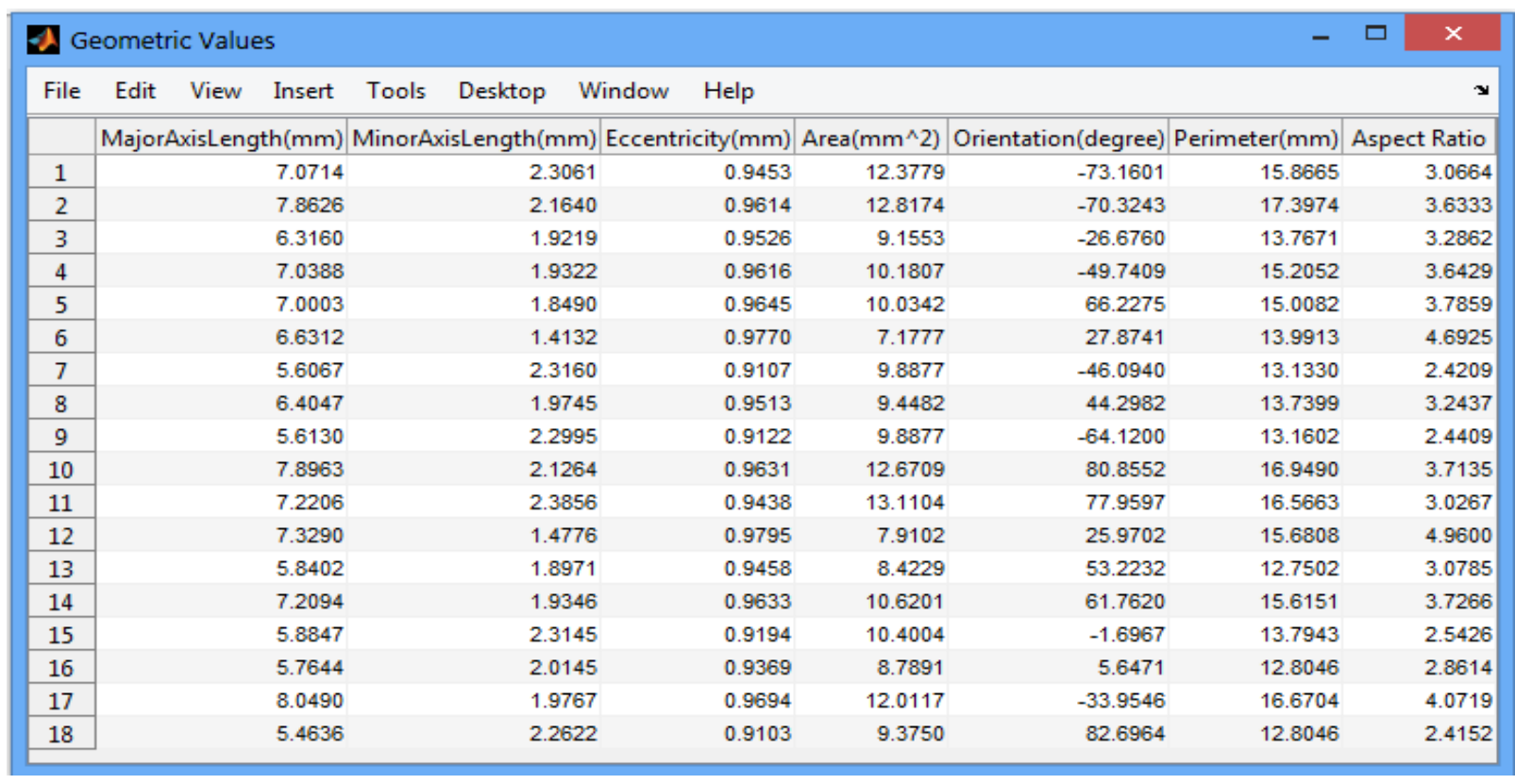

Table II. Geometric Features of rice grains

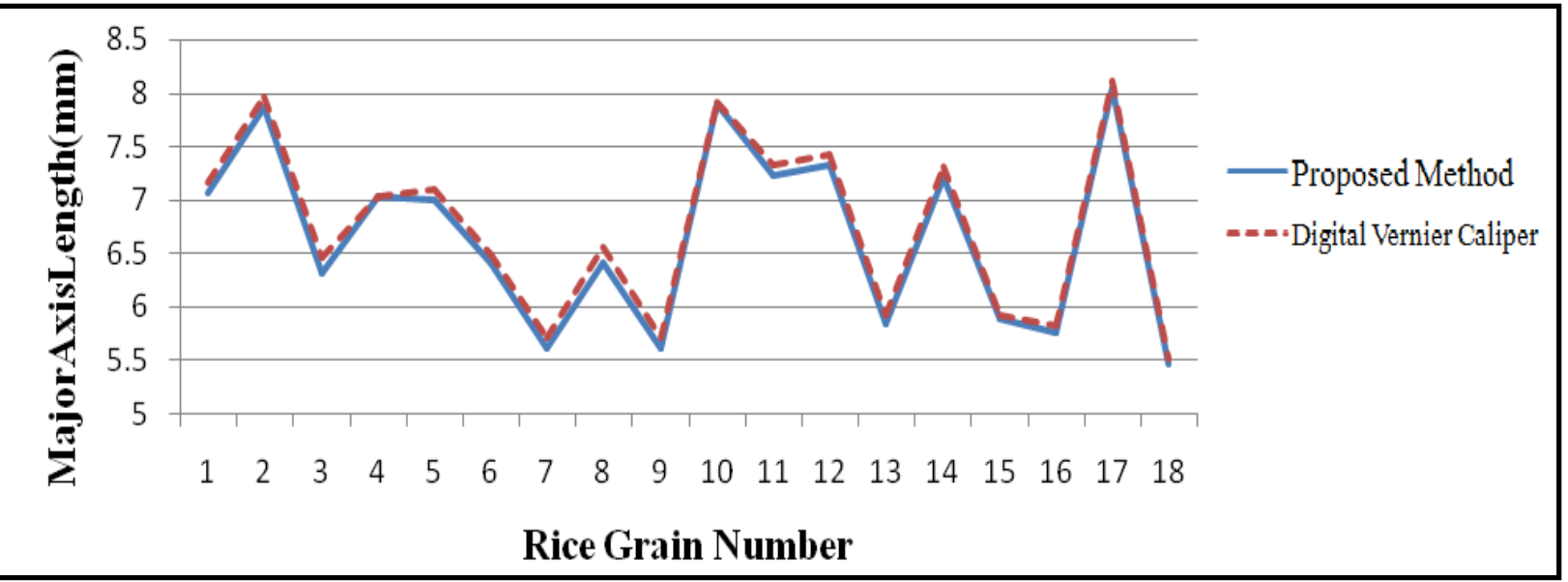

Fig.3. Comparison of Major axis length of Pusa basmati 1509 rice grains found by proposed method and digital vernier caliper

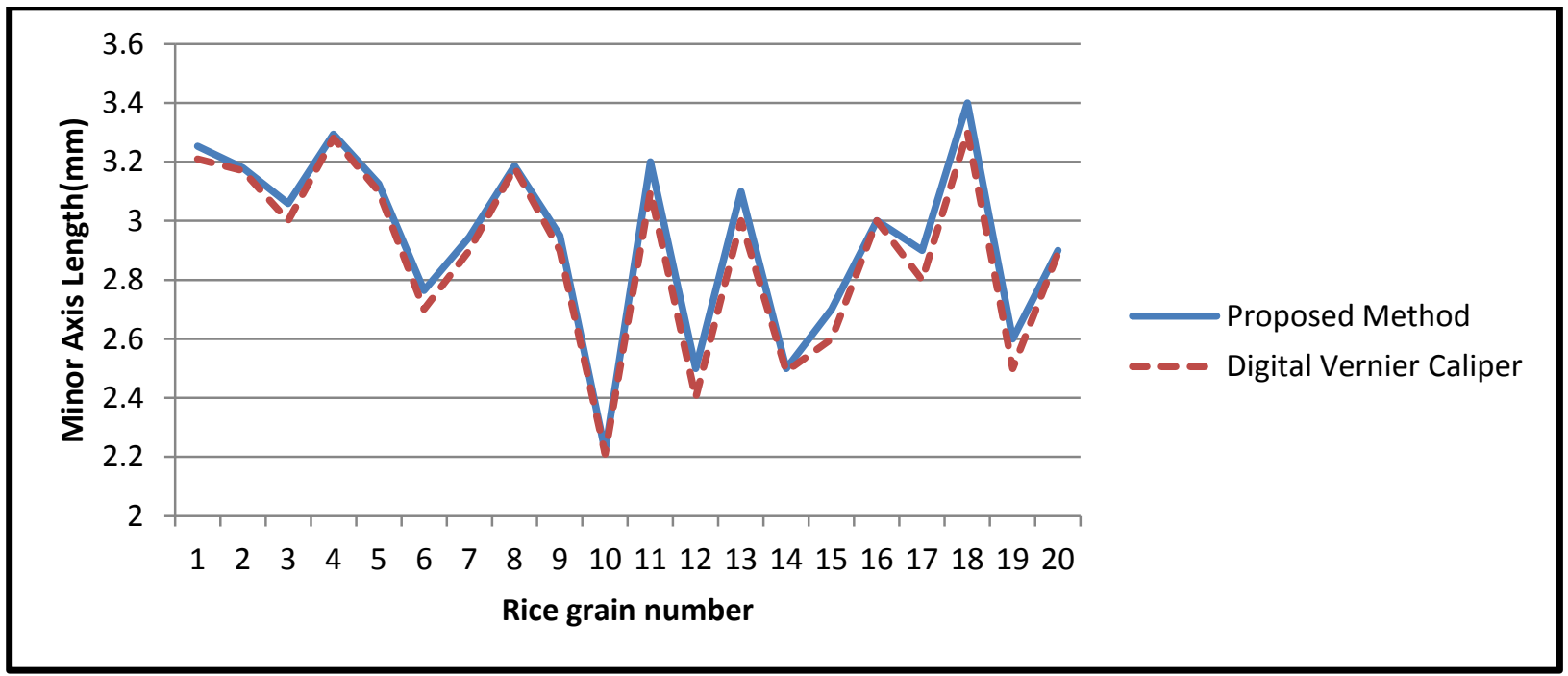

Fig.4. Comparison of Minor axis length of Pusa basmati 1121 rice grains calculated by proposed method and digital vernier caliper 


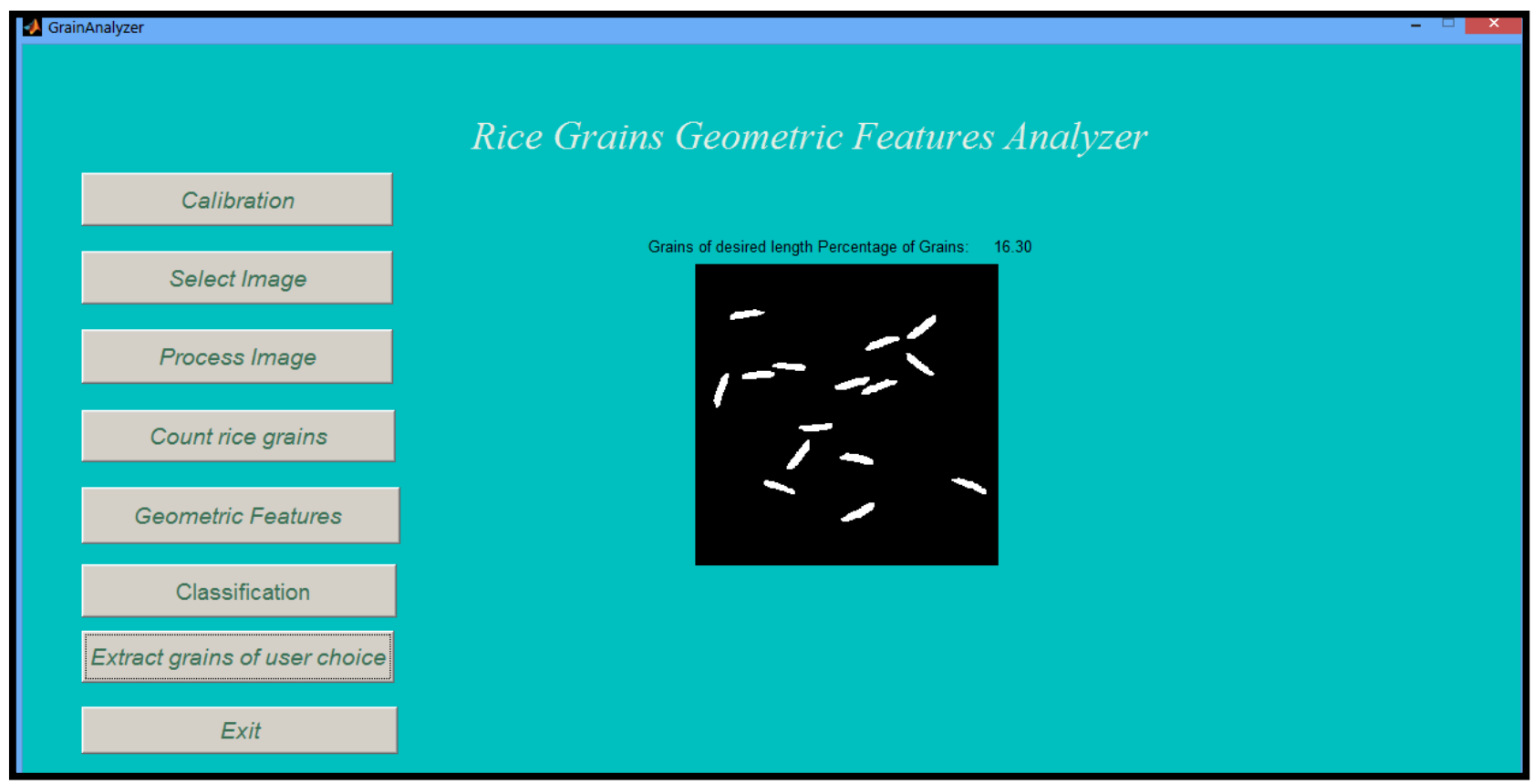

Fig.5.Screenshot

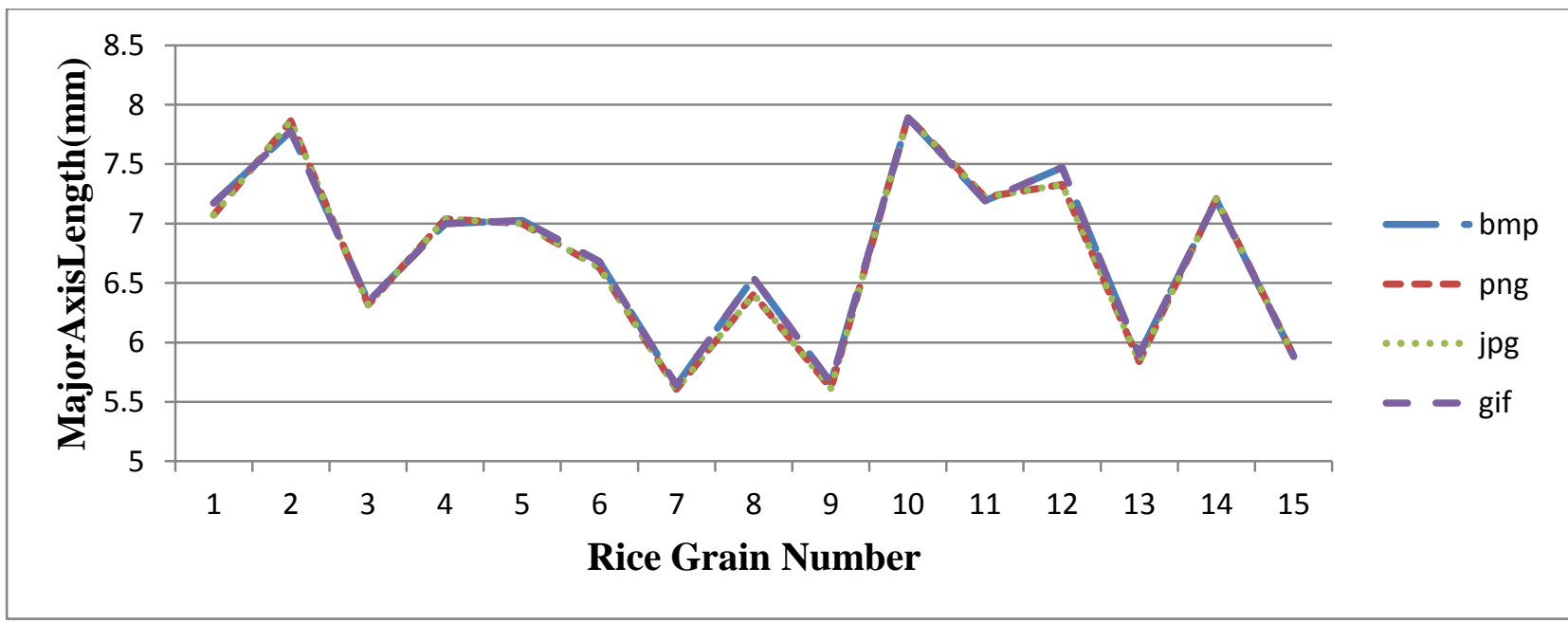

Fig.6. Comparison of Major axis length of Pusa basmati 1509 rice grains in different image formats.

\section{CONCLUSION}

The developed application is independent of camera position and effectively identifies seven geometrical features (Major axis length, Minor axis length, eccentricity, area, orientation, perimeter, aspect ratio) of the selected five different rice grain varieties. Features were extracted after performing basic functions on digital image. Based on Major axis length it further classifies the rice grains into three classes. The developed approach is useful to identify the percentage of different Major axis length rice grains in a sample. The error rate of measuring different geometric features between proposed method and experimental analysis is found between $-1.39 \%$ and $1.40 \%$.

The work in future can be extended by finding other quality features of rice grains and working on moving images.

\section{REFERENCES}

[1] Brosnan T and Sun D W (2002) Inspection and grading of agricultural and food products by computer vision systems - a review. Computers and Electronics in Agriculture 36:193-213.

[2] Camelo GA (2012) et al Digital image analysis of diverse Mexican rice cultivars .Journal of the Science of Food and Agriculture 92:2709-2714.

[3] Gujjar H S and Siddappa M (2013) A Method for identification of basmati rice grain of India and its quality using pattern classification. International Journal of Engineering Research and Applications 3:268-273. 
[4] Guzman J D and Peralta E K (2008) Classification of Philippine rice grains using machine vision and artificial neural networks. World Conference on Agricultural Information and IT 19:41-48.

[5] Kaur G, Din S, Brar A S and Singh D (2014) Scanner image analysis to estimate leaf area. International Journal of Computer Applications 107:5-10.

[6] Kaur H, Singh B (2013) Classification and grading rice using multi-class svm. International Journal of Scientific and Research Publications 3:1-5.

[7] Liu Z Y, Cheng F J, Ying Y B and Rao X Q (2005) Identification of rice seed varieties using neural network. Journal of Zhejiang University Science 11: 1095-1100.

[8] Maheshwari C V, Jain K R and Modi C K (2012) Nondestructive quality analysis of Indian Gujrat-17 oryza sativa ssp indica (rice) using image processing. International Journal of Computer Engineering Science 2:48-54.

[9] Patil N K, Malemath V S and Yadahalli R M (2011) Color and texture based identification and classification of food grains using different color models and haralick features. International Journal on Computer Science and Engineering 3:3669-3680.

[10] Shantaiya S and Ansari U (2010) Identification of food grains and its quality using pattern classification. International Journal of Computer \& Communication Technology 2:70-74.

[11] Singh T, Kumar CM, Singh P and Kumar P (2013) Advances in computer vision technology for foods of animal and aquatic origin- a review. Journal of Meat Science and Technology 1:40-49. 